\title{
Danaparoid sodium-based anticoagulation therapy for portal vein thrombosis in cirrhosis patients
}

\author{
Takehiro Hayashi ${ }^{1,2}$, Hajime Takatori ${ }^{1 *}$, Rika Horii ${ }^{1}$, Kouki Nio ${ }^{1}$, Takeshi Terashima ${ }^{1}$, Noriho lida ${ }^{1}$, Masaaki Kitahara', \\ Tetsuro Shimakami ${ }^{1}$, Kuniaki Arai ${ }^{1}$, Kazuya Kitamura ${ }^{1}$, Kazunori Kawaguchi ${ }^{1}$, Taro Yamashita ${ }^{1}$, Yoshio Sakai ${ }^{1}$, \\ Tatsuya Yamashita', Eishiro Mizukoshi ${ }^{1}$, Masao Honda ${ }^{1}$, Tadashi Toyama ${ }^{3}$, Kenichiro Okumura ${ }^{4}$, Kazuto Kozaka ${ }^{4}$ and \\ Shuichi Kaneko ${ }^{1}$
}

\begin{abstract}
Background: Portal vein thrombosis (PVT) is a common complication of cirrhosis. However, in patients with PVT and cirrhosis, there is no clear evidence supporting effective treatment modalities. In this study, we examined the effectiveness and safety of anticoagulation therapy using danaparoid sodium for PVT in patients with cirrhosis.

Methods: This retrospective study assessed 52 cirrhotic patients with PVT treated with danaparoid sodium for 2 weeks between November 2008 and September 2018. The primary outcome measure was the post-treatment status of PVT assessed by reduction in thrombus volume and safety of the therapeutic intervention. PVT status was evaluated with contrast-enhanced computed tomography (CECT). All patients received 1250 units of danaparoid sodium twice daily by intravenous injection for 14 days. Patients on antithrombin III (AT-III) combination therapy were additionally administered 1500 units of AT-III on days 1-5 and days 8-12. Effectiveness was evaluated by CECT from between days 13 and 18 . The secondary outcome measure was the prognosis of PVT.
\end{abstract}

Results: All patients showed reduction in PVT volume without complications. Return of plasma AT-III level to $>70 \%$ during the treatment period contributes to $\geq 75 \%$ reduction of PVT volume. The prognosis in PVT patients depends on hepatic reserve capacity. When limited to Child-Pugh B and C liver cirrhosis patients, a $\geq 75 \%$ reduction of PVT volume improved the prognosis.

Conclusions: Danaparoid sodium-based anticoagulation therapy was effective and safe for PVT in patients with cirrhosis. Return of plasma AT-III level to the normal range during the treatment period contributes to reduction of PVT volume. A reduction of $\geq 75 \%$ in PVT volume may improve the prognosis of Child-Pugh B and C decompensated cirrhosis patients with PVT.

Keywords: Portal vein thrombosis, Liver cirrhosis, Danaparoid sodium, Antithrombin III

\section{Background}

Portal vein thrombosis (PVT) is characterized by thrombus formation in the trunk of the portal vein involving its right and left intrahepatic branches. The thrombus may even extend to the splenic or superior mesenteric vein or toward the liver involving the intrahepatic portal branches [1]. PVT may occur in various

\footnotetext{
*Correspondence: takatori@m-kanazawa.jp

${ }^{1}$ Department of Gastroenterology, Kanazawa University Graduate School of Medical Science, Kanazawa, Ishikawa, Japan

Full list of author information is available at the end of the article
}

clinical pathologies, such as cirrhosis, myeloproliferative disease, cancer, and infection [2]. PVT is a common complication of cirrhosis, with prevalence ranging from 0.6 to $15.8 \%$ in patients with liver cirrhosis or portal hypertension [3]. Advanced or decompensated cirrhosis and hepatobiliary malignancy are especially high-risk conditions for PVT, and patients with both cirrhosis and hepatic carcinoma are considered to have the highest risk for PVT [4].

PVT has various clinical presentations, ranging from asymptomatic to life-threatening conditions, such as 
gastroesophageal bleeding and acute intestinal ischemia $[3,5]$. Furthermore, PVT is reported to be associated with an increased risk of ascites and mortality risk in patients with cirrhosis [6].

The treatment of PVT should be tailored according to the patient's background. However, in patients with PVT and cirrhosis, no evidence supports the use of anticoagulation therapy because of the risk of bleeding due to reduced synthesis of coagulation factors and high incidence of varices and portal hypertensive gastropathy $[1,2,7]$.

Current treatment modalities for PVT mainly include anticoagulation, systemic and local thrombolysis, percutaneous portal vein recanalization, and transjugular intrahepatic portosystemic shunt $[3,8]$. Recent reports have shown that anticoagulation therapy for PVT is safe, with low rates of complication. For example, danaparoid sodium and antithrombin III (AT-III) are effective and safe for treating PVT in patients with liver disease [9-13].

Danaparoid sodium is an anticoagulant that works by inhibiting activated factor Xa. A major advantage of danaparoid is its low rate of cross-reactivity with antibodies associated with immune-mediated heparininduced thrombocytopenia [14]. Further, it has been reported that danaparoid sodium is unlikely to cause gastrointestinal hemorrhage, and it appears to be more effective and safer than heparin in terms of bleeding complications [15].

In this study, we examined the effectiveness of anticoagulation therapy using danaparoid sodium in PVT in patients with cirrhosis.

\section{Methods}

\section{Patients}

This retrospective study involved 55 cirrhotic patients with PVT treated with danaparoid sodium between November 2008 and September 2018. PVT was defined as the occurrence of thrombosis in the main trunk of the portal vein or the first-order vessels of the left (LPV) or right (RPV) branch of the portal vein or superior mesenteric vein (SMV). We excluded 1 patient with portal vein tumor thrombus and 2 patients for whom plasma AT-III levels were not examined. Finally, 52 patients who received danaparoid sodium-based anticoagulation therapy for 2 weeks as initial treatment were included in the study. All enrolled patients received routine clinical management of PVT at Kanazawa University Hospital. PVT patients were treated with danaparoid sodium with AT-III (combination therapy) or without ATIII (monotherapy). From November 2008 to September 2011, we used combination therapy to treat PVT. From October 2011 to March 2014, we used monotherapy. Also, from April 2014 to September 2018, patients with an AT-III of $\leq 70 \%$ received combination therapy, and those with an AT-III $>70 \%$ received monotherapy. Accordingly, 22 and 30 PVT patients were treated with combination therapy or monotherapy, respectively.

Table 1 shows the clinical characteristics of cirrhotic patients with PVT before treatment. In brief, all patients were clinically diagnosed with cirrhosis. We classified hepatocellular carcinoma (HCC) stage based on the UICC TNM classification algorithm for HCC [16]. In this study, cases with no recurrence following curative treatment were designated absence of HCC. We classified esophageal and gastric varices based on the general rules for endoscopic findings of esophagogastric varices [17] (Table 1).

Table 2 shows the characteristics of PVT. In brief, most thromboses ( $84 \%$ of 52 patients) were located completely or partially within the main trunk of the portal vein. The portal vein was completely obstructed by thrombus in 6 cases (11\%). Severity of occlusion was classified according to Bauer's Classification [18]. Treatment was started $\leq 30$ days of diagnosis in 32 patients (62\%). The timing of development of PVT was $\leq 90$ days before diagnosis in 14 patients (27\%) (Table 2).

Regarding events that could cause PVT and occurred $\leq 90$ days prior to diagnosis, PVT was thought to be

Table 1 Baseline characteristics of patients

\begin{tabular}{|c|c|}
\hline & $n=52$ \\
\hline Sex (male / female) & $40 / 12$ \\
\hline Mean age (years) & $65 \pm 9$ \\
\hline Etiology (HBV / HCV / HBV + HCV / NBNC) & $7 / 29 / 1 / 15$ \\
\hline Child-Pugh score (A / B / C) & $13 / 25 / 14$ \\
\hline Hepatocellular carcinoma (absent / present) & $31 / 21$ \\
\hline \multicolumn{2}{|l|}{ UICC Stage of hepatocellular carcinoma } \\
\hline Absent (none / after curative treatment) & $19 / 12$ \\
\hline Present (Stage I / II / III / IV) & $8 / 12 / 0 / 1$ \\
\hline Esophageal varices (absent / present) & $1 / 51$ \\
\hline Monotherapy / Combination therapy & $30 / 22$ \\
\hline White blood cell count $(/ \mu \mathrm{L})$ & $3773 \pm 1994$ \\
\hline Hemoglobin (g/dL) & $11.2 \pm 1.8$ \\
\hline Platelet count $\left(\times 10^{4} / \mu \mathrm{L}\right)$ & $9.0 \pm 6.4$ \\
\hline Albumin (mg/dL) & $3.1 \pm 0.5$ \\
\hline Total bilirubin (mg/dL) & $1.6 \pm 1.1$ \\
\hline Aspartate aminotransferase (IU/L) & $46 \pm 24$ \\
\hline Alanine aminotransferase (IU/L) & $32 \pm 19$ \\
\hline Gamma-glutamyl transpeptidase (IU/L) & $47 \pm 59$ \\
\hline Prothrombin time (\%) & $64 \pm 14$ \\
\hline Prothrombin time/International normalized ratio & $1.3 \pm 0.2$ \\
\hline Fibrinogen degradation product $(\mu \mathrm{g} / \mathrm{mL})$ & $15.7 \pm 17.1$ \\
\hline D-dimer $(\mu \mathrm{g} / \mathrm{mL})$ & $7.5 \pm 8.1$ \\
\hline Antithrombin III (\%) & $58 \pm 17$ \\
\hline
\end{tabular}


Table 2 Characteristics of portal vein thrombosis

\begin{tabular}{|c|c|c|}
\hline Site of portal vein thrombosis & $n=52$ & \\
\hline MPV & 11 & $21 \%$ \\
\hline MPV + intrahepatic branch & 17 & $32 \%$ \\
\hline$M P V+S M V$ & 6 & $11 \%$ \\
\hline MPV + SMV + intrahepatic branch & 3 & $6 \%$ \\
\hline$M P V+S V$ & 2 & $4 \%$ \\
\hline MPV + SV + intrahepatic branch & 2 & $4 \%$ \\
\hline$M P V+S M V+S V$ & 2 & $4 \%$ \\
\hline $\mathrm{MPV}+\mathrm{SMV}+\mathrm{SV}+$ intrahepatic branch & 1 & $2 \%$ \\
\hline SMV & 2 & $4 \%$ \\
\hline SMV + intrahepatic branch & 1 & $2 \%$ \\
\hline RPV & 2 & $4 \%$ \\
\hline LPV & 2 & $4 \%$ \\
\hline$L P V+S V$ & 1 & $2 \%$ \\
\hline Degree of portal vein thrombosis & $n=52$ & \\
\hline Partial obstruction & 46 & $89 \%$ \\
\hline Complete obstruction & 6 & $11 \%$ \\
\hline Bauer's Classification & $n=52$ & \\
\hline Grade I & 0 & $0 \%$ \\
\hline Grade II & 15 & $29 \%$ \\
\hline Grade III & 26 & $50 \%$ \\
\hline Grade IV & 11 & $21 \%$ \\
\hline Period from diagnosis to treatment & $n=52$ & \\
\hline$\leq 30$ days & 32 & $62 \%$ \\
\hline$>31$ days & 20 & $38 \%$ \\
\hline $\begin{array}{l}\text { Period from last test not showing } \\
\text { thrombosis to treatment }\end{array}$ & $n=52$ & \\
\hline$\leq 90$ days & 14 & $27 \%$ \\
\hline $91-180$ & 12 & $23 \%$ \\
\hline$>181$ days & 14 & $27 \%$ \\
\hline Undetermined & 12 & $23 \%$ \\
\hline
\end{tabular}

MPV Main portal vein, SMV Superior mesenteric vein, SV splenic vein, RPV Right portal vein, LPV Left portal vein

associated with treatment of HCC in 9 patients (17\%) and with variceal events in 7 patients (13\%). PVT was associated with infection in 3 patients $(6 \%)$ and with arterioportal shunt in 1 patient (2\%); the cause was unidentifiable in 32 patients (62\%) (Table 3$)$.

\section{Protocol for treatment of portal vein thrombosis}

All patients with PVT included in this study received an intravenous injection of 1250 units of danaparoid sodium (Orgaran; MSD, Tokyo, Japan) twice daily for 2 weeks. Patients belonging to the combination therapy group received an additional drip infusion of AT-III (Nonthron; Nihon Pharmaceutical, Tokyo, Japan) at a dose of 1500 units/day from day 1 to day 5 and from day 8 to day 12 (Fig. 1a).

\section{Evaluation of PVT}

All patients underwent contrast-enhanced computed tomography (CECT) to evaluate for the presence of PVT. We traced the thrombus on an axial CECT image and calculated the volume of the thrombus by using a 3dimensional image analysis system (Synapse Vincent Ver. 3 and Ver. 5; Fujifilm Medical Co., Tokyo, Japan). Effectiveness was evaluated by CECT between days 13 and 18. Measurement was confirmed by a radiology technologist and the attending physician. PVT volume reduction rate was based on the following calculation:

PVT reduction rate $=\{($ PVT volume before treatment - volume after treatment) / (PVT volume before treatment) $\} \times 100$ (Fig. 1b).

\section{Data collection}

We reviewed patients' medical records and collected demographic, clinical, and laboratory data, including age, sex, hepatitis virus status, hepatic reserve, and imaging data. The Institutional Review Board of Kanazawa University Hospital approved the study's treatment strategy and study protocol and all patients provided written informed consent for inclusion in the study (No. 2016096). The study was conducted in accordance with the Declaration of Helsinki.

\section{Statistical analysis}

Statistical analysis was performed with GraphPad Prism software 6.0 (GraphPad Software, San Diego, CA). Categorical variables were compared using the $\chi^{2}$-test when appropriate. Student's t-test was used for continuous variables. Survival rates were analyzed using the KaplanMeier method with the log-rank test. All $P$ values were two-tailed, and $P<0.05$ was considered statistically significant.

\section{Results}

Safety and effectiveness of danaparoid sodium treatment for PVT and effects on the fibrinolytic system

In this study, the primary outcome measures were reduction in PVT volume and safety of the therapeutic intervention. Regarding thrombus volume, after 2 weeks of danaparoid sodium-based anticoagulation therapy, all patients showed considerable reduction in the posttreatment volume of the thrombus compared with the pretreatment volume. PVT volume was significantly decreased from $6.1 \pm 8.9 \mathrm{~mL}$ to $2.5 \pm 7.4 \mathrm{~mL} \quad(P<0.0001$, Fig. 2a). The mean reduction rate of PVT volume was $72 \%$; the distribution of reduction rate of PVT is shown in Fig. $2 b$.

We considered combination therapy and monotherapy separately. For monotherapy, PVT volume decreased significantly from $5.1 \pm 10.1 \mathrm{~mL}$ to $2.9 \pm 9.5 \mathrm{~mL}(P<0.0001$, Fig. 2c), and the distribution of reduction rate of PVT is 
Table 3 Probable cause of PVT

\begin{tabular}{lll}
\hline Probable cause & $n=52$ & \\
\hline Associated with hepatocellular carcinoma & 9 & $17 \%$ \\
RFA & 4 & \\
PEIT & 1 & \\
IH Chemo & 2 & $13 \%$ \\
Surgery & 1 & \\
Angio CT & 1 & \\
Associated with varices & 7 & \\
Varix rupture & 3 & \\
EVL & 2 & \\
EIS & 1 & \\
BRTO & 1 & \\
AP shunt & 1 & $62 \%$ \\
Infection & 3 & \\
Biliary tract infection & 1 & \\
Intestinal infection & 1 & \\
Upper respiratory tract infection & 1 & \\
Unknown & 32 &
\end{tabular}

RFA Radiofrequency ablation, PEIT Percutaneous ethanol injection therapy, IH Chemo, Intrahepatic chemotherapy, Angio CT Computed tomographic angiography, EVL Endoscopic variceal ligation, EIS Endoscopic injection sclerotherapy, BRTO Balloon-occluded retrograde transvenous obliteration, AP shunt Arterioportal shunt

shown in Fig. 2d. For combination therapy, PVT volume decreased significantly from $6.7 \pm 7.2 \mathrm{~mL}$ to $2.2 \pm 3.1 \mathrm{~mL}$ $(P=0.0001$, Fig. $2 \mathrm{e})$, and the distribution of reduction rate of PVT is shown in Fig. $2 f$.

\section{Effect on the fibrinolytic system and complications}

Regarding safety of the therapeutic intervention, we evaluated fibrinolytic system function using fibrinogen degradation products (FDP) $(n=50)$, and fibrinogen degradation products-D dimer (FDP-DD) $(n=50)$. Patients for whom these values were unavailable were excluded from this analysis. FDP changed from $15.7 \pm 17.1 \mu \mathrm{g} / \mathrm{mL}$ to $3.9 \pm$ $3.8 \mu \mathrm{g} / \mathrm{mL}(P<0.0001$, Fig. 3a) and FDP-DD changed from $7.5 \pm 8.1 \mu \mathrm{g} / \mathrm{mL}$ to $1.7 \pm 1.6 \mu \mathrm{g} / \mathrm{mL} \quad(\mathrm{P}<0.0001$, Fig. $3 \mathrm{~b})$; the levels decreased significantly at the end of the treatment.

In this study, we defined major bleeding as clinically overt bleeding associated with any of the following: fatal outcome; involvement of a critical anatomic site (intracranial, spinal, ocular, pericardial, articular, retroperitoneal, or intramuscular with compartment syndrome); fall in hemoglobin level $>2 \mathrm{~g} / \mathrm{dL}$; or requiring transfusion of $>2 \mathrm{U}$ of whole blood; or packed red blood cells [19]. All patients completed the treatment without the occurrence of major bleeding, thrombocytopenia, or liver dysfunction. The mean hemoglobin level during treatment was $11.3 \pm 1.8 \mathrm{~g} / \mathrm{dL}$ before treatment and $11.2 \pm 1.9 \mathrm{~g} / \mathrm{dL}$ at the end of treatment (Fig. 3c).

Platelet count during treatment was $9.0 \pm 6.4 \times 10^{4} / \mu \mathrm{L}$ before treatment and $9.3 \pm 6.4 \times 10^{4} / \mu \mathrm{L}$ at the end of treatment (Fig. 3d). No significant differences were noted in hemoglobin levels and platelet count during the treatment period.

\section{Factors associated with a $75 \%$ reduction of portal vein thrombosis volume}

The mean reduction rate of PVT volume was $72 \%$, we determined therapeutic effectiveness cases (effective group) as a reduction of $\geq 75 \%$ in the volume of the thrombus by volume as compared to the pretreatment volume. Treatment was considered ineffective (ineffective group) if the reduction in the thrombus volume was $<75 \%$.

We investigated factors associated with $\mathrm{a} \geq 75 \%$ reduction of PVT volume. Plasma AT-III level was $57.8 \pm$ $18.7 \%$ in the ineffective group and $58.0 \pm 16.6 \%$ in the effective group, and there was no significant difference (Fig. 4a). Normal plasma AT-III level was defined as > $70 \%$. We compared whether pretreatment AT-III levels were within normal range in the ineffective and effective groups; no significant difference was noted (Fig. 4b). There was also no significant difference in use of AT-III (Fig. 4c). We examined plasma AT-III level measured during the treatment period. There were significantly more cases where treatment was effective for AT-III levels $>70 \%$ during the treatment period $(P=0.0426$, Fig. 4d). For patients with plasma AT-III level $\leq 70 \%$ before treatment, it was considered important to correct to normal plasma AT-III level by using AT-III concurrently.

We investigated the relationship between portal vein occlusion rate and therapeutic effect. There was no significant difference between partial or complete portal vein occlusion (Fig. 4e). We compared patients with Bauer's Classification grades II and III with grade IV patients and found no significant difference (Fig. 4f). Although the difference was not significant, there were 8 cases (19.5\%) of complete dissolution of thrombus among the Bauer's Classification II and III patients but none among Bauer's Classification IV patients (Fig. 4g).

\section{Prognosis of portal vein thrombosis patients}

Although the sample size was small, we attempted to investigate prognosis in PVT patients as the secondary outcome measure. We examined hepatic reserve capacity (Compensated cirrhosis (Child-Pugh A) or decompensated cirrhosis (Child-Pugh B or C)), presence of HCC, and treatment effects of danaparoid-based anticoagulation therapy. Hepatic reserve capacity affected the prognosis in PVT patients; Child-Pugh A patients had significantly 


\section{(A)}

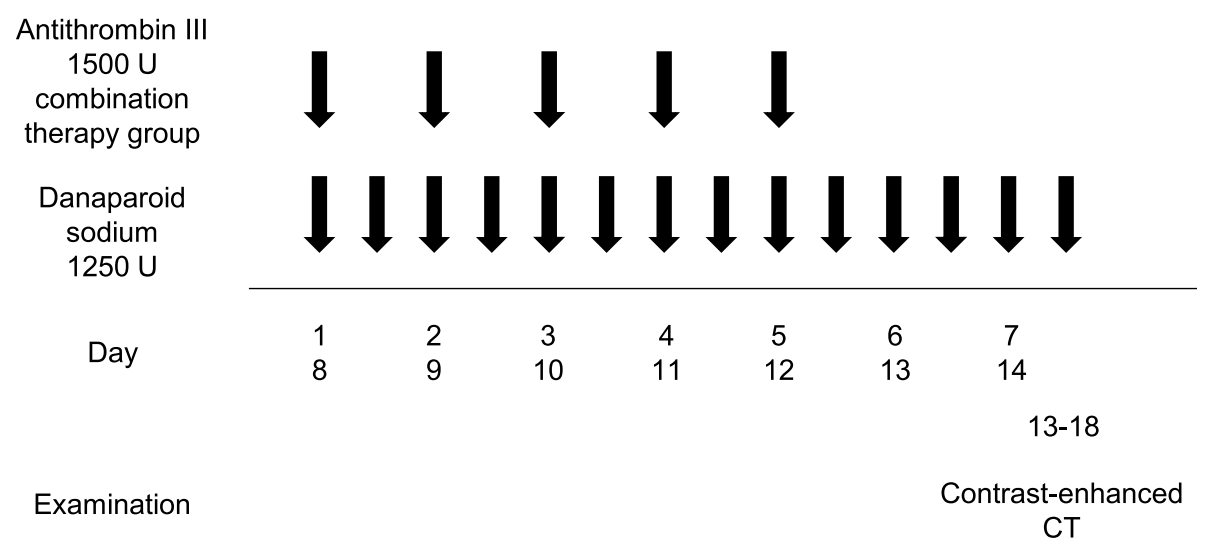

(B)

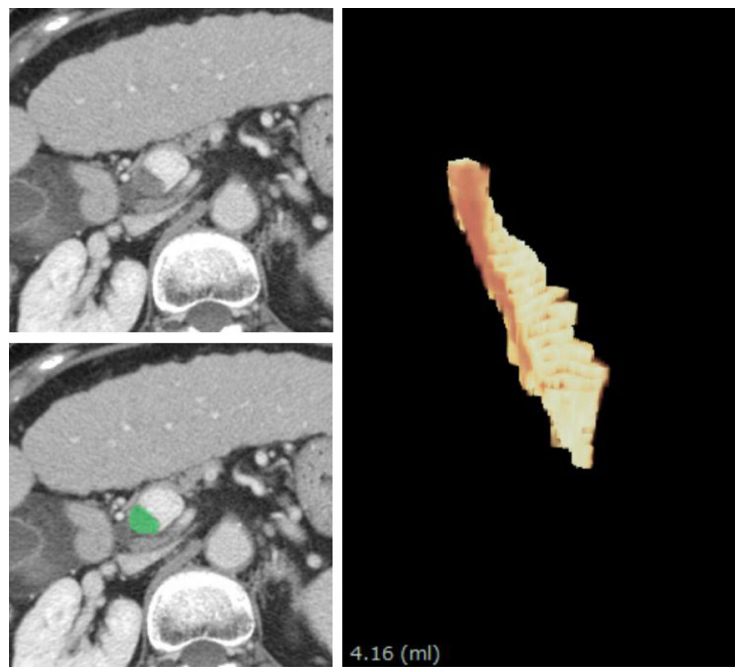

Fig. 1 Protocol of danaparoid sodium-based anticoagulation therapy. a Patients received intravenous injection of 1250 units of danaparoid sodium twice daily for 2 weeks. Patients belonging to the combination therapy group received additional infusion of AT-III at 1500 units/day from day 1 to day 5 and from day 8 to day 12. PVT was evaluated by using contrast-enhanced computed tomography at the end of 2 weeks of treatment (between days 13 and 18). $\mathbf{b}$ Measurement of PVT volume. The thrombus was traced on an axial CECT image and the volume of the thrombus was calculated using a 3-dimensional image analysis system (Synapse Vincent Ver. 3 and Ver. 5; Fujifilm Medical Co., Tokyo, Japan)

better prognosis than Child-Pugh $\mathrm{B}$ and $\mathrm{C}$ patients $(P=$ 0.0127, Fig. 5a). Treatment effects $(P=0.7128$, Fig. 5b) and presence of HCC ( $P=0.0618$, Fig. $5 \mathrm{c})$ did not affect prognosis in this cohort. Thus, prognosis in PVT cases depends on hepatic reserve capacity.

Because of the poor prognosis in decompensated cirrhosis, we examined prognosis for only cases with ChildPugh B and C decompensated cirrhosis. Treatment effects of PVT affected prognosis of PVT in Child-Pugh B and $C$ cases, and the treatment effective group had better prognosis than the ineffective group $(P=0.0179$, hazard ratio: 0.22 , Fig. $5 \mathrm{~d}$ ). The presence of HCC did not affect prognosis in this cohort $(P=0.2475$, Fig. 5e). Table 4 shows a comparison between clinical characteristics of Child-Pugh B and C patients in the treatment effective group $(n=20)$ and ineffective group $(n=19)$. There was no difference in the ineffective group. On the other hand, in Child-Pugh A compensated cirrhosis patients, the effects of treatment of PVT $(P=0.0589$, Fig. 5f $)$ and the presence of $\operatorname{HCC}(P=$ 0.3189 , Fig. $5 g$ ) did not affect prognosis.

These results suggested the possibility that $\mathrm{a} \geq 75 \%$ reduction of PVT volume may improve prognosis in ChildPugh B and C decompensated cirrhosis patients with PVT, and danaparoid sodium-based anticoagulation therapy should be considered for such patients. With a hazard ratio of 0.22 , the ratio of each group would be $1: 1$, the event rate would be $38 \%$, and the number of cases would 

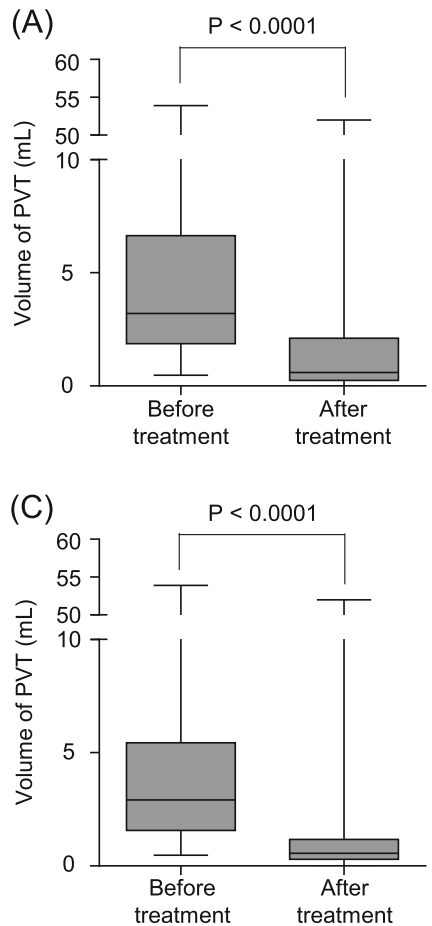

(E)

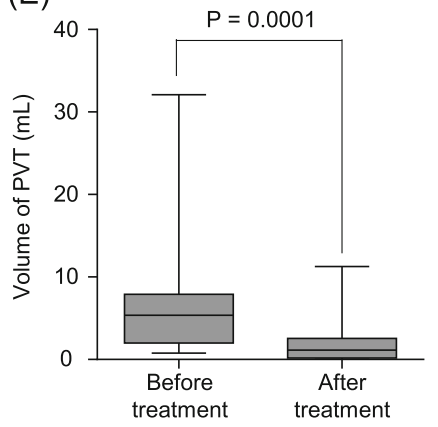

(B)

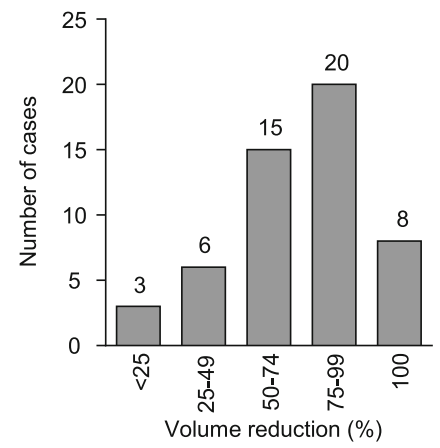

(D)

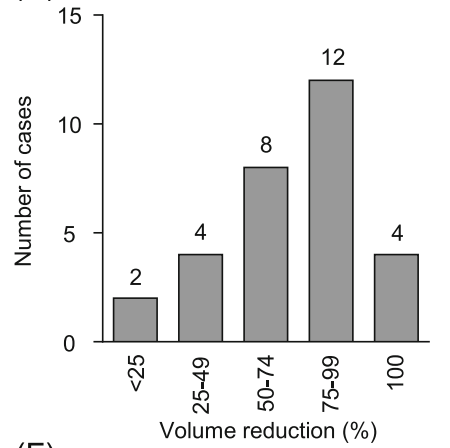

$(\mathrm{F})$

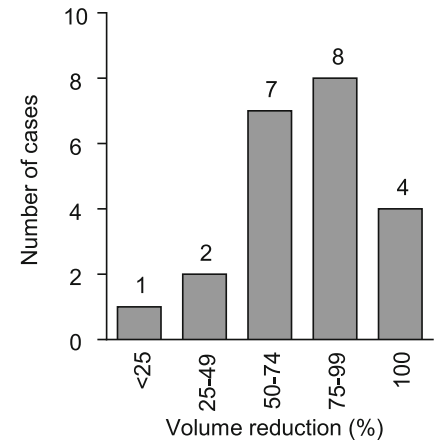

Fig. 2 Effectiveness of danaparoid sodium-based anticoagulation therapy. a Reduction in the post-treatment volume of the thrombus compared with the pre-treatment volume in all patients. PVT volume significantly decreased from $6.1 \pm 8.9 \mathrm{~mL}$ to $2.5 \pm 7.4 \mathrm{~mL}(P<0.0001)$. b Distribution of volume change in all patients. $\mathbf{c}$ Reduction in the post-treatment volume of the thrombus compared with the pre-treatment volume in monotherapy group. PVT volume significantly decreased from $5.1 \pm 10.1 \mathrm{~mL}$ to $2.9 \pm 9.5 \mathrm{~mL}(P<0.0001)$. d Distribution of volume change in the monotherapy group. e Reduction in the post-treatment volume of the thrombus compared with the pre-treatment volume in the combination therapy group. PVT volume significantly decreased from $6.7 \pm 7.2 \mathrm{~mL}$ to $2.2 \pm 3.1 \mathrm{~mL}(P=0.0001)$. f Distribution of volume change in the combination therapy group

be 39. With a two-sided $5 \%$-level test, the power was $82 \%$ and so we consider this test result to be reliable.

\section{Discussion}

In the present study, we assessed the effectiveness of danaparoid sodium-based anticoagulation therapy for PVT in patients with cirrhosis. This study demonstrated that all the patients who received danaparoid sodium-based anticoagulation therapy showed reduction of PVT volume. Recent studies have reported that low-molecular-weight heparin and vitamin $\mathrm{K}$ antagonists constitute the two main types of anticoagulants for the treatment of PVT, with a portal vein recanalization rate of $42-100 \%[9,20-25]$; and metaanalysis showed a portal recanalization rate of $66.6 \%$ [26]. In this study, all patients showed reduction of PVT volume following treatment. Most of the cases in this cohort were in the acute stage without portal cavernoma, and this may explain the good treatment outcomes. Another report measured PVT reduction by volume and the reduction rate was $100 \%$ [9], but the method for evaluating treatment effectiveness in thrombosis may have differed among past papers. Unification of the treatment evaluation method seems necessary for future advances in PVT treatment. Thus, danaparoid sodium-based anticoagulation therapy may be 

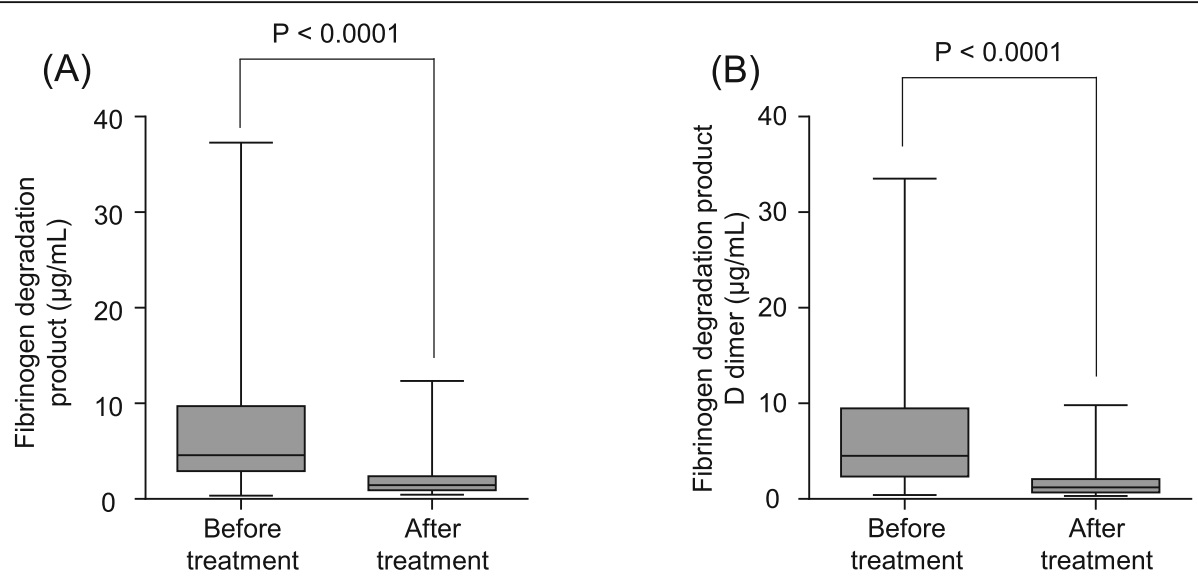

(C)

(D)
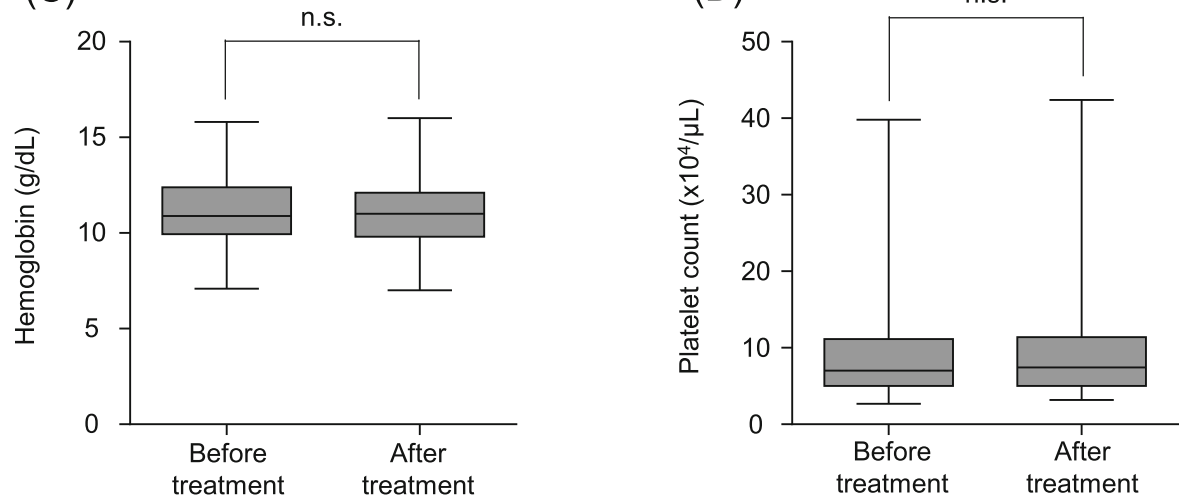

Fig. 3 Effect on the fibrinolytic system and time course of hemoglobin levels and platelet counts. a FDP changed from $15.7 \pm 17.1 \mu \mathrm{g} / \mathrm{mL}$ before treatment to $3.9 \pm 3.8 \mu \mathrm{g} / \mathrm{mL}$ at the end of treatment. The FDP level was significantly decreased $(P<0.0001) . \mathbf{b}$ FDP-DD changed from $7.5 \pm 8.1 \mu \mathrm{g} / \mathrm{mL}$ before treatment to $1.7 \pm 1.6 \mu \mathrm{g} / \mathrm{mL}$ at the end of treatment. The FDP-DD level was significantly decreased $(P<0.0001)$. $\mathbf{c}$ Hemoglobin levels changed from $11.3 \pm 1.8 \mathrm{~g} / \mathrm{dL}$ before treatment to $11.2 \pm 1.9 \mathrm{~g} / \mathrm{dL}$ at the end of treatment. The hemoglobin level showed no significant difference. $\mathbf{d}$ Platelet counts changed from $9.0 \pm 6.4 \times 10^{4} / \mu \mathrm{L}$ before treatment to $9.3 \pm 6.4 \times 10^{4} / \mu \mathrm{L}$ at the end of treatment, and showed no significant difference

an equally or more effective treatment as compared with low-molecular-weight heparin and vitamin $\mathrm{K}$ antagonists.

Considering the high risk of bleeding due to the reduced synthesis of coagulation factors and presence of esophageal and gastric varices, portal hypertensive gastropathy, and gastric antral vascular ectasia in cirrhotic patients, danaparoid sodium may offer greater safety compared with other anticoagulation agents. In fact, no patients experienced bleeding events in this cohort. Cirrhotic patients generally have low platelet counts due to hypersplenism, and it is well known that using heparin can cause heparin-induced thrombocytopenia. However, in the present study of danaparoid sodium-based anticoagulation therapy, thrombocytopenia was not observed in any of the patients.

A disadvantage of danaparoid sodium-based anticoagulation therapy is that patients require frequent hospital visits or hospitalization because danaparoid sodium is administered as an intravenous injection. Recently, new oral anticoagulation agents that target factor Xa, such as apixaban, rivaroxaban, and edoxaban, have become available [27-29], and these may emerge as novel treatment options for PVT.

In this cohort, after danaparoid sodium treatment, 20 patients were given anticoagulant therapy using vitamin $\mathrm{K}$ antagonists and 11 patients were treated with edoxaban. A recent report described the usefulness of maintenance treatment with edoxaban [10]. There are no established criteria for the use of anticoagulant therapy and drug selection after treatment in this cohort, and so further studies on the effectiveness of maintenance treatment with such cases will be needed.

However, there were 21 cases that had not received maintenance treatment. In 1 of these cases, the residual PVT after treatment disappeared after 2 months. A detailed study of transient PVT was recently reported [30]. The PVT in this 1 case may have been transient PVT and may have resolved without anticoagulant therapy. Further study will be needed regarding how to identify which cases of PVT require treatment. 

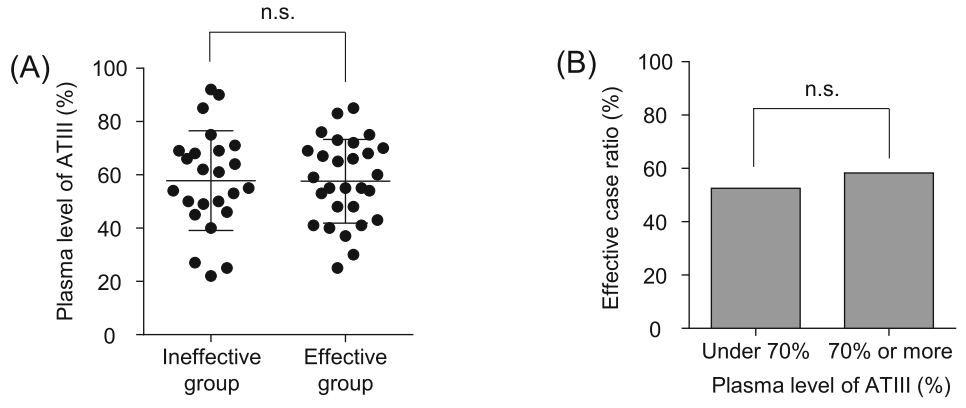

(C)

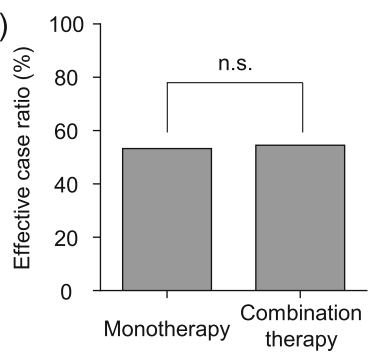

(E)

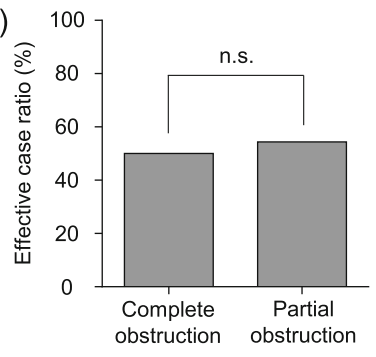

(G)

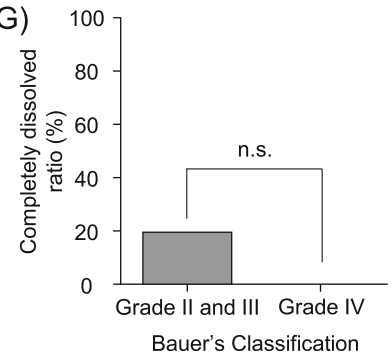

(D)

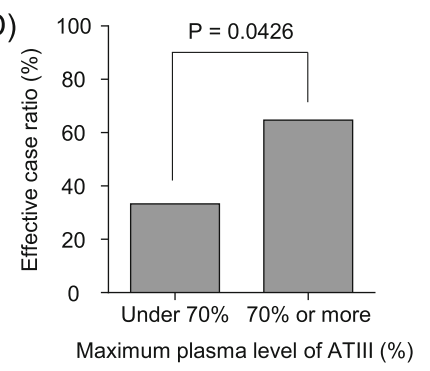

(F)

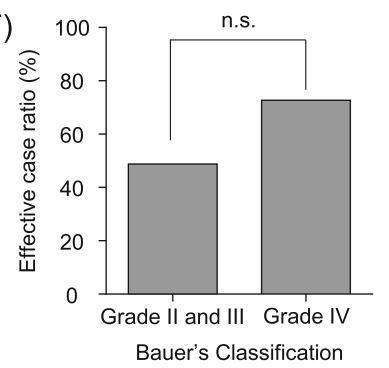

Fig. 4 Factors affecting 75\% reduction of portal vein thrombosis volume. a Plasma AT-III level was $59.5 \pm 1.9 \%$ and $60.4 \pm 14.8 \%$ in the ineffective and effective groups, respectively, with no significant difference. $\mathbf{b}$ No significant difference is seen regarding whether pretreatment AT-III level was within normal range or not in both groups. $\mathbf{c}$ No significant difference is seen regarding use of AT-III or not. $\mathbf{d}$ Significantly more cases where treatment was effective for AT-III level $>70 \%$ during the treatment period $(P=0.0426)$. e No significant difference is seen between partial or complete portal vein occlusion. $\mathbf{f}$ No significant difference is seen in comparisons between Bauer's Classification grade II and III patients and grade IV patients. g Although the difference was not significant there were 8 patients (19.5\%) with completely dissolved thrombus among Bauer's Classification II and III patients but none among the Bauer's Classification IV patients

To achieve $\mathrm{a} \geq 75 \%$ reduction of PVT volume, it is considered important that a plasma AT-III level $\leq 70 \%$ be corrected to a normal level by administering AT-III concurrently. AT-III (Nonthron) at a dose of 1500 units is an expensive drug that costs 59,753 JPY per 1500 units. Therefore, we propose that it be used in patients with AT-III of $\leq 70 \%$ and not in all cases, and recommend that additional administration be evaluated by monitoring the AT-III level.

Although this cohort included many cases complicated by HCC, this study showed that treatment of PVT using danaparoid sodium improved prognosis in Child-Pugh B and $\mathrm{C}$ decompensated cirrhosis if PVT volume reduced by $\geq 75 \%$ compared with the pre-treatment volume. 


\section{(A)}

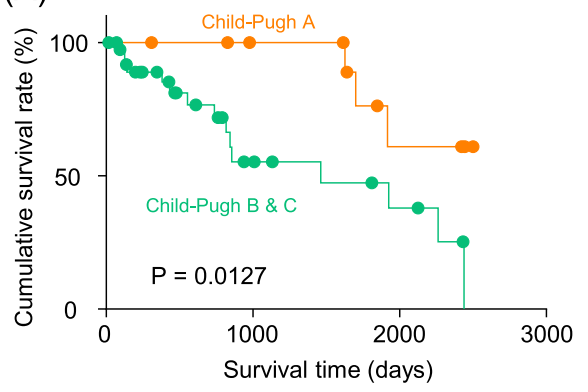

(C)

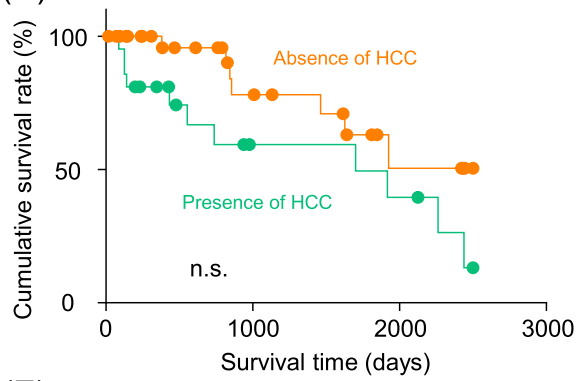

(E)

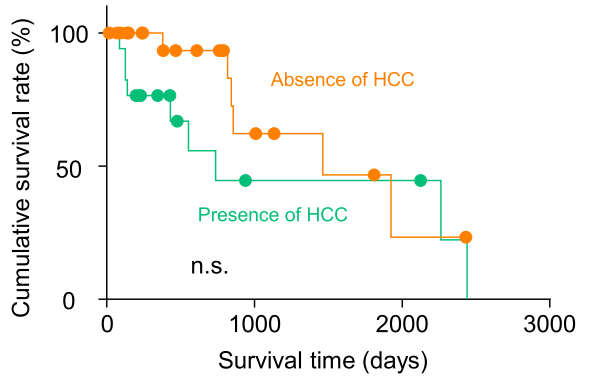

(G)

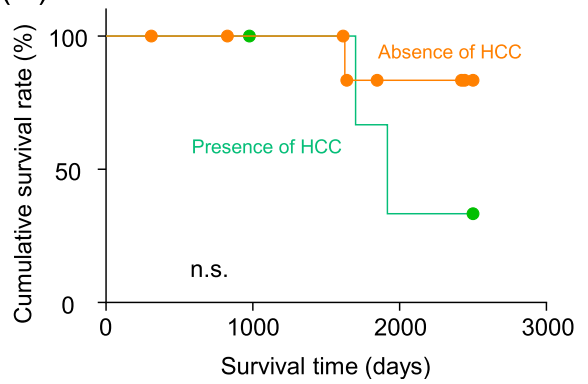

(B)

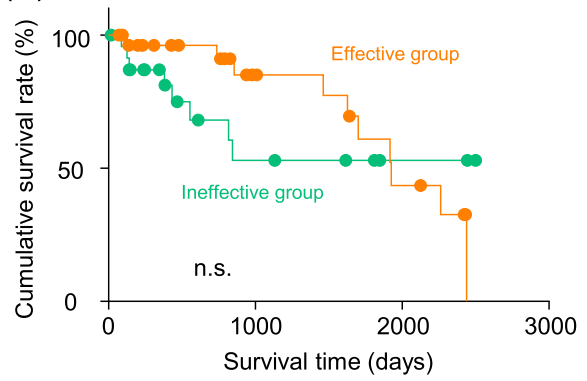

(D)

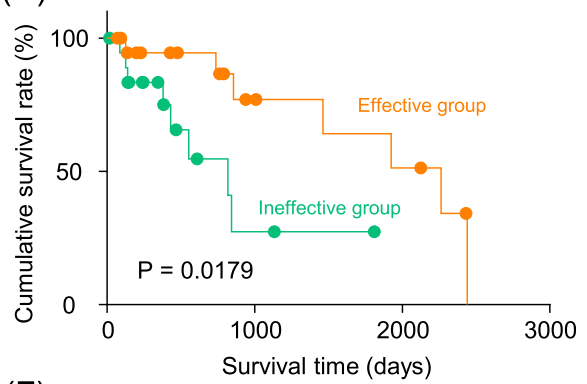

(F)

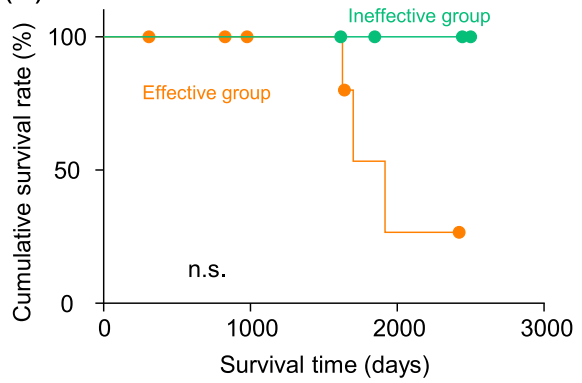

Fig. 5 Prognosis of cirrhosis patients with portal vein thrombosis. a Compared by hepatic reserve capacity: Compensated cirrhosis (Child-Pugh A, $n=13$ ) patients show significantly better prognosis than decompensated cirrhosis (Child-Pugh $B$ and $C, n=39)$ patients $(P=0.0127)$. b Compared by treatment effect: No significant difference is seen between the effective group $(n=28)$ and ineffective groups $(n=24)(P=0.7128)$. c Compared by presence of HCC: No significant difference is seen between presence of HCC $(n=21)$ and absence of HCC $(n=31)(P=0.0618)$. $\mathbf{d}$ Compared by treatment effect in Child-Pugh B and C decompensated cirrhosis: Effective group $(n=20)$ shows significantly better prognosis than ineffective group $(n=19)(P=0.0179)$. e Compared by presence of HCC in Child-Pugh B and C decompensated cirrhosis: These is no significant difference between presence of HCC $(n=17)$ and absence of HCC $(n=22)(P=0.2475)$. $\mathbf{f}$ Compared by treatment effect in Child-Pugh A compensated cirrhosis: These is no significant difference between the effective group $(n=8)$ and ineffective groups $(n=5)(P=0.0589)$. $\mathbf{g}$ Compared by presence of HCC in Child-Pugh A compensated cirrhosis: no significant difference is seen between presence of HCC ( $n=4)$ and absence of HCC $(n=9)(P=0.3189)$ 
Table 4 Characteristics of Child-Pugh B and C decompensated cirrhosis patients

\begin{tabular}{|c|c|c|c|}
\hline & Effective group $(n=20)$ & Ineffective group $(n=19)$ & $P$ value \\
\hline Sex (male / female) & $18 / 2$ & $13 / 6$ & n.s. \\
\hline Mean age (years) & $66 \pm 8$ & $67 \pm 10$ & n.s. \\
\hline Etiology (HBV / HCV / HBV + HCV / NBNC) & $2 / 11 / 1 / 4$ & 2/9/0/8 & n.s. \\
\hline Child-Pugh score (B / C) & $12 / 8$ & $13 / 6$ & n.s. \\
\hline Hepatocellular carcinoma (absent / present) & $10 / 10$ & $12 / 7$ & n.s. \\
\hline \multicolumn{4}{|l|}{ UICC stage of hepatocellular carcinoma } \\
\hline Absent (none / after curative treatment) & $5 / 5$ & $8 / 4$ & \\
\hline Present (Stage I / II / III / IV) & $1 / 8 / 0 / 1$ & $4 / 3 / 0 / 0$ & \\
\hline Esophageal varices (absent / present) & $0 / 20$ & $1 / 18$ & n.s. \\
\hline Monotherapy / Combination therapy & $8 / 12$ & $11 / 8$ & n.s. \\
\hline White blood cell count $(/ \mu \mathrm{L})$ & $4177 \pm 2631$ & $3352 \pm 1218$ & n.s. \\
\hline Hemoglobin (g/dL) & $11.2 \pm 1.5$ & $10.8 \pm 2.0$ & n.s. \\
\hline Platelet count $\left(\times 10^{4} / \mu \mathrm{L}\right)$ & $9.5 \pm 7.7$ & $7.2 \pm 3.7$ & n.s. \\
\hline Albumin (mg/dL) & $2.9 \pm 0.3$ & $3.0 \pm 0.4$ & n.s. \\
\hline Total bilirubin (mg/dL) & $1.9 \pm 1.2$ & $1.8 \pm 1.2$ & n.s. \\
\hline Aspartate aminotransferase (IU/L) & $54 \pm 35$ & $44 \pm 14$ & n.s. \\
\hline Alanine aminotransferase (IU/L) & $36 \pm 28$ & $29 \pm 13$ & n.s. \\
\hline Gamma-glutamyl transpeptidase (IU/L) & $52 \pm 58$ & $51 \pm 77$ & n.s. \\
\hline Prothrombin time (\%) & $60 \pm 10$ & $63 \pm 15$ & n.s. \\
\hline Prothrombin time/International normalized ratio & $1.3 \pm 0.2$ & $1.3 \pm 0.2$ & n.s. \\
\hline Fibrinogen degradation product $(\mu \mathrm{g} / \mathrm{mL})$ & $16.5 \pm 19.7$ & $16.8 \pm 11.6$ & n.s. \\
\hline D-dimer $(\mu \mathrm{g} / \mathrm{mL})$ & $8.4 \pm 9.7$ & $7.7 \pm 5.7$ & n.s. \\
\hline Antithrombin III (\%) & $53 \pm 16$ & $55 \pm 19$ & n.s. \\
\hline
\end{tabular}

NBNC non-B, non-C

However, this cohort was small, and regarding the prognosis, further studies are needed.

\section{Conclusions}

Danaparoid sodium-based anticoagulation therapy was effective and safe for PVT in patients with cirrhosis. Return of plasma AT-III level to normal range during the treatment period contributes to $\mathrm{a} \geq 75 \%$ reduction of PVT volume. The prognosis in PVT patients depends on hepatic reserve capacity. Anticoagulation therapy for PVT by danaparoid sodium in Child-Pugh B and C decompensated cirrhosis patients, $\mathrm{a} \geq 75 \%$ reduction of PVT volume may improve the prognosis.

\section{Abbreviations}

AT-III: Antithrombin III; CECT: Contrast-enhanced computed tomography; FDP: Fibrinogen degradation products; FDP-DD: Fibrinogen degradation products-D dimer; HCC: Hepatocellular carcinoma; LPV: Left branch of the portal vein; PVT: Portal vein thrombosis; RPV: Right branch of portal vein; SMV: Superior mesenteric vein

\section{Acknowledgements}

Not applicable.
Authors' contributions

All authors helped to perform the research. TH, HT, and SK contributed to the study design. $\mathrm{TH}$ and $\mathrm{HT}$ contributed to data acquisition and analysis. $\mathrm{RH}$, KN, TT, NI, MK, TS, KA, KKi, KKo, TarY, YS, TatY, EM, MH, OK, KKa, and SK discussed the interpretation of the data. $\Pi$ contributed to statistical analysis. OK and KKa contributed to image analysis. TH and HT wrote the manuscript. All authors read and approved the final version of the manuscript.

\section{Funding}

Not applicable.

Availability of data and materials

The datasets used and/or analyzed during the study are available from the corresponding author on reasonable request.

Ethics approval and consent to participate

The study's treatment strategy and protocol were approved by the Institutional Review Board of Kanazawa University Hospital and all patients provided written informed consent to participate in the study. The study was conducted in accordance with the tenets of the Declaration of Helsinki.

Consent for publication

Not applicable.

\section{Competing interests}

The authors declare that they have no competing interests.

\section{Author details}

${ }^{1}$ Department of Gastroenterology, Kanazawa University Graduate School of Medical Science, Kanazawa, Ishikawa, Japan. ${ }^{2}$ Department of 
Gastroenterology, Yawata Medical Center, Komatsu, Ishikawa, Japan. ${ }^{3}$ Department of Nephrology, Kanazawa University Graduate School of Medical Science, Kanazawa, Ishikawa, Japan. ${ }^{4}$ Department of Radiology, Kanazawa University Graduate School of Medical Science, Kanazawa, Ishikawa, Japan.

Received: 22 January 2019 Accepted: 9 December 2019

Published online: 16 December 2019

\section{References}

1. Chawla YK, Bodh V. Portal vein thrombosis. J Clin Exp Hepatol. 2015;5(1):22-40.

2. DeLeve LD, Valla DC, Garcia-Tsao G. American Association for the Study Liver D: vascular disorders of the liver. Hepatol. 2009;49(5):1729-64.

3. Kinjo N, Kawanaka H, Akahoshi T, Matsumoto Y, Kamori M, Nagao Y, Hashimoto N, Uehara $\mathrm{H}$, Tomikawa M, Shirabe K, et al. Portal vein thrombosis in liver cirrhosis. World J Hepatol. 2014;6(2):64-71.

4. Ogren M, Bergqvist D, Bjorck M, Acosta S, Eriksson H, Sternby NH. Portal vein thrombosis: prevalence, patient characteristics and lifetime risk: a population study based on 23,796 consecutive autopsies. World J Gastroenterol. 2006;12(13):2115-9.

5. Condat B, Pessione F, Hillaire S, Denninger M-H, Guillin M-C, Poliquin M, Hadengue A, Erlinger S, Valla D. Current outcome of portal vein thrombosis in adults: risk and benefit of anticoagulant therapy. Gastroenterology. 2001; 120(2):490-7.

6. Stine JG, Shah PM, Cornella SL, Rudnick SR, Ghabril MS, Stukenborg GJ, Northup PG. Portal vein thrombosis, mortality and hepatic decompensation in patients with cirrhosis: a meta-analysis. World J Hepatol. 2015;7(27):2774-80.

7. de Franchis R. Evolving consensus in portal hypertension. Report of the Baveno IV consensus workshop on methodology of diagnosis and therapy in portal hypertension. J Hepatol. 2005;43(1):167-76.

8. Qi X, Han G, Fan D. Management of portal vein thrombosis in liver cirrhosis. Nat Rev Gastroenterol Hepatol. 2014;11(7):435-46.

9. Naeshiro N, Aikata H, Hyogo H, Kan H, Fujino H, Kobayashi T, Fukuhara T, Honda Y, Nakahara T, Ohno A, et al. Efficacy and safety of the anticoagulant drug, danaparoid sodium, in the treatment of portal vein thrombosis in patients with liver cirrhosis. Hepatol Res. 2015;45(6):656-62.

10. Nagaoki Y, Aikata H, Daijyo K, Teraoka Y, Shinohara F, Nakamura Y, Hatooka M, Morio K, Nakahara T, Kawaoka T, et al. Efficacy and safety of edoxaban for treatment of portal vein thrombosis following danaparoid sodium in patients with liver cirrhosis. Hepatol Res. 2018;48(1):51-8.

11. Hidaka H, Kokubu S, Sato T, Katsushima S, Izumi N, Igura T, Asahara S, Notsumata K, Osaki Y, Tsuji K, et al. Antithrombin III for portal vein thrombosis in patients with liver disease: a randomized, double-blind, controlled trial. Hepatol Res. 2017.

12. Kojima S, Watanabe N, Koizumi J, Kokubu S, Murashima N, Matsutani S, Obara K. Current status of portal vein thrombosis in Japan: results of a questionnaire survey by the Japan Society for Portal Hypertension. Hepatol Res. 2017.

13. Fujiyama S, Saitoh S, Kawamura Y, Sezaki H, Hosaka T, Akuta N, Kobayashi M, Suzuki Y, Suzuki F, Arase $Y$, et al. Portal vein thrombosis in liver cirrhosis: incidence, management, and outcome. BMC Gastroenterol. 2017;17(1):112.

14. Frangos SG, Chen AH, Sumpio B. Vascular drugs in the new millennium. J Am Coll Surg. 2000;191(1):76-92.

15. Nakase J, Toribatake Y, Mouri Y, Seki H, Kitaoka K, Tomita K. Heparin versus danaproid for prevention of venous thromboembolism after hip surgery. $J$ Orthop Surg (Hong Kong). 2009;17(1):6-9.

16. Sobin LH. WC: International Union against Cancer (UICC) TNM classification of malignant tumours. 7th ed. New York: Wiley; 2009.

17. Tajiri T, Yoshida H, Obara K, Onji M, Kage M, Kitano S, Kokudo N, Kokubu S, Sakaida I, Sata M, et al. General rules for recording endoscopic findings of esophagogastric varices (2nd edition). Dig Endosc : Official J Japan Gastroenterol Endosc Soc. 2010;22(1):1-9.

18. Bauer J, Johnson S, Durham J, Ludkowski M, Trotter J, Bak T, Wachs M. The role of TIPS for portal vein patency in liver transplant patients with portal vein thrombosis. Liver Transpl. 2006;12(10):1544-51.

19. Schulman S, Kearon C. Definition of major bleeding in clinical investigations of antihemostatic medicinal products in non-surgical patients. J Thromb Haemost : JTH. 2005;3(4):692-4.

20. Delgado MG, Seijo S, Yepes I, Achecar L, Catalina MV, Garcia-Criado A, Abraldes JG, de la Pena J, Banares R, Albillos A, et al. Efficacy and safety of anticoagulation on patients with cirrhosis and portal vein thrombosis Clinical Gastroenterol Hepatol : Official Clin Pract J Am Gastroenterol Assoc. 2012;10(7):776-83

21. Maruyama H, Takahashi M, Shimada T, Yokosuka O. Emergency anticoagulation treatment for cirrhosis patients with portal vein thrombosis and acute variceal bleeding. Scand J Gastroenterol. 2012;47(6):686-91.

22. Werner KT, Sando S, Carey EJ, Vargas HE, Byrne TJ, Douglas DD, Harrison ME, Rakela J, Aqel BA. Portal vein thrombosis in patients with end stage liver disease awaiting liver transplantation: outcome of anticoagulation. Dig Dis Sci. 2013;58(6):1776-80.

23. Senzolo M. T MS, Rossetto V, Burra P, Cillo U, Boccagni P, Gasparini D, Miotto D, Simioni $P$, Tsochatzis $E$ et al: prospective evaluation of anticoagulation and transjugular intrahepatic portosystemic shunt for the management of portal vein thrombosis in cirrhosis. Liver Int : Official J Int Assoc Study Liver. 2012;32(6):919-27.

24. Amitrano L, Guardascione MA, Menchise A, Martino R, Scaglione M, Giovine S, Romano L, Balzano A. Safety and efficacy of anticoagulation therapy with low molecular weight heparin for portal vein thrombosis in patients with liver cirrhosis. J Clin Gastroenterol. 2010;44(6):448-51.

25. Francoz C, Belghiti J, Vilgrain V, Sommacale D, Paradis V, Condat B, Denninger MH, Sauvanet A, Valla D, Durand F. Splanchnic vein thrombosis in candidates for liver transplantation: usefulness of screening and anticoagulation. Gut. 2005;54(5):691-7.

26. Qi X, De Stefano V, Li H, Dai J, Guo X, Fan D. Anticoagulation for the treatment of portal vein thrombosis in liver cirrhosis: a systematic review and meta-analysis of observational studies. Eur J Intern Med. 2015;26(1):23-9

27. Agnelli G, Buller HR, Cohen A, Curto M, Gallus AS, Johnson M, Porcari A, Raskob GE, Weitz JI, Investigators P-E. Apixaban for extended treatment of venous thromboembolism. N Engl J Med. 2013;368(8):699-708.

28. Bauersachs R, Berkowitz SD, Brenner B, Buller HR, Decousus H, Gallus AS, Lensing AW, Misselwitz F, Prins MH, Raskob GE, et al. Oral rivaroxaban for symptomatic venous thromboembolism. N Engl J Med. 2010;363(26):2499_ 510.

29. Buller HR, Decousus H, Grosso MA, Mercuri M, Middeldorp S, Prins MH, Raskob GE, Schellong SM, Schwocho L, Segers A, et al. Edoxaban versus warfarin for the treatment of symptomatic venous thromboembolism. N Engl J Med. 2013;369(15):1406-15.

30. Qi X, Guo X, Yoshida EM, Mendez-Sanchez N, De Stefano V, Tacke F, Mancuso A, Sugawara Y, Yang SS, Teschke R, et al. Transient portal vein thrombosis in liver cirrhosis. BMC Med. 2018;16(1):83.

\section{Publisher's Note}

Springer Nature remains neutral with regard to jurisdictional claims in published maps and institutional affiliations.

Ready to submit your research? Choose BMC and benefit from:

- fast, convenient online submission

- thorough peer review by experienced researchers in your field

- rapid publication on acceptance

- support for research data, including large and complex data types

- gold Open Access which fosters wider collaboration and increased citations

- maximum visibility for your research: over $100 \mathrm{M}$ website views per year

At $\mathrm{BMC}$, research is always in progress.

Learn more biomedcentral.com/submissions 